\section{ESTUDO COMPARATIVO DE INDICADORES BIOQUIMICOS DE CONCENTRAÇÃO DE FERRO, EM DUAS POPULAÇÕES DE GESTANTES, COM E SEM ATENDIMENTO PRÉ-NATAL}

\footnotetext{
SZARFARC, S.C. et al. Estudo comparativo de indicadores bioquímicos de concentracão de ferro, em duas populaçōes de gestantes, com e sem atendimento pré-natal. Rev. Saúde públ., S. Paulo, 16:1-6, 1982,
}

RESUMO: Foi avaliada a influéncia da quantidade do atendimento pré-natal na deficiência de ferro entre gestantes com 36 e mais semanas de gravidez, em comparação com un grupo padrão. A amostra foi distribuída em 3 grupos: GP - com pré-natal de "acreditação" satisfatória (grupo padrão); CPN com pré-natal, de diferentes qualidades; SPN - sem pré-natal. Os resultados obtidos para hemoglobina mostraram que no grupo padrão (GP) a prevalência e severidade de anemia são significativamente menores do que no grupo com pré-natal (CPN) e este do que no sem pré-natal (SPN). Os resultados obtidos na relação hemoglobina/hematócrito, ferro sérico e capacidade total de ligação de ferro apresentaram o GP em situação significativamente melhor do que os grupos CPN e SPN que não foram estatisticamente diferentes entre si. Chamou-se a atenção para a necessidade de aumento de cobertura e uniformização na qualidade dos serviços de pré-natal, com o objetivo de diminuir a prevalência de deficjência de ferro entre gestantes.

UNITERMos: Gestantes, estado nutricional. Anemia ferropriva. Assistência pré-natal.

\title{
INTRODUÇÃO
}

A associação da deficiência de ferro com eventos patológicos na gravidez e a grande prevalência com que essa patologia ocorre, permitem justificar a posição de destaque com que a anemia ferropriva figura entre os problemas de saúde pública no grupo gestante.

A anemia, que ocorre em 21 a $80 \%$ das gestantes do mundo ${ }^{14}$, onera o risco graví- dico. Entre outros, Delascio e Almeida 5 classificam a anemia severa como um dos fatores que pode acarretar um feto de alto risco; Nesbitt e Aubry'situam-na como fator de risco obstétrico de importância equivalente, por exemplo, à desnutriçāo energética, à pré diabete, entre outros; em diferentes sistemas de quantificação de risco gravídico ${ }^{5,6, \pi, 10,15}$ a anemia se apresenta como fator de relevante importância.

\footnotetext{
* Do Departamento de Nutrição da Facul :ade de Saúde Pública da USP - Av. Dr. Arnaldo. 715 - 01255 - São Paulo, SP - Brasil.

*: Do Departamento de Saúde Materno-Infantil da Faculdade de Saúde Pública da USP - Av. Dr. Arnaldo, 715 - 01255 - São Paulo, SP -Brasil.
} 
SZARFARC, S.C, et al. Estt:do comparativo de indicadores bioquímicos de concentração de ferro, em duas populações de gestantes, com e sem atendimento pré-natal, Rev. Saúde públ., S. Paulo, 16:1-6, 1982.

Se é grande a prevalência de anemia entre grávidas, maior é a freqüência com que a deficiência de ferro aparece. A OMS $1+$ refere que 40 a $99 \%$ das gestantes do mundo são ferro-deficientes. Szarfarc e col.13 em estudo realizado com o objetivo de conhecer a evolução de indices bioquimicos do ferro, no decorrer da gravidez, entre mulheres não anêmicas, verificaram que a depleção dos estoques de ferro é fenômeno comum a esse grupo populacional, ocorrendo mesmo entre mulheres não anêmicas.

A Secretaria de Estado de Saúde de São Paulo ${ }^{9}$, no seu programa de assistência à gestante, define como uma das atividades de assistência à população alvo a suplementação férrica, com o objetivo de "promover a melhoria da assistência à gestação, parto e puerpério mediante atendimento precoce, periódico e contínuo" através de consultas médicas de rotina, num nínimo de 3 por gestação.

Tendo em vista a importância da anemia ferropriva como problema de saúde pública e a consulta pré-natal como um mecanismo capaz de detectar e corrigir essa deficiência nutricional, este trabalho visa conhecer a influência das consultas de pré-natal no que se refere aos indices bioquimicos relacionados ao ferro em população de grávidas assistidas no parto, em maternidade exclusivamente assistencial, e, comparativamente, a um grupo padrão.

\section{MATERIAL E METODOS}

Para atender o objetivo proposto foi escolhida uma população de mulheres atendidas no parto, na maternidade da Fundação Amparo Maternal, tendo como comparação um grupo de gestantes, com 36 semanas ou mais de gravidez, atendidas no Serviço de Pré-Natal do Centro de Saúde-Escola Geraldo de Paula Souza da Faculdade de Saúde Pública da Universidade de São Paulo, cuja qualidade de serviço é satisfatória 4 .
As grávidas que participaram do estudo foram distribuidas em três grupos:

Grupo Padrão (GP) - constituído por 74 gestantes escolhidas por amostragem casual dentre as atendidas regularmente no Centro de Saúde Geraldo de Paula Souza. Grupo com Pré-Natal (CPN) - constituido por 77 gestantes que receberam 3 ou mais consultas de pré-natal, em diferentes serviços de saúde.

Grupo sem Pré-Natal (SPN) - constituido por 77 gestantes que referiram 2 ou menos consultas de pré-natal.

As mulheres dos grupos CPN e SPN foram escolhidas, por amostragem casual, na Fundação Amparo Maternal e sua distribuição nos dois grupos, obedece ao critério proposto por Ciari e Almeida ${ }^{3}$.

Foi colhida amostra de sangue venoso de todas as mulheres e medidos os índices bioquímicos: hemoglobina $(\mathrm{Hb})$, concentração de hemoglobina corpuscular média ( $\mathrm{CHCM})$, através da relação entre hemoglobina e hematócrito, ferro sérico (FS) 2 e saturação da transferrina (ST) através da relaçāo entre ferro sérico e capacidade total de ligação de ferro ${ }^{*}$.

Os resultados obtidos foram comparados através da estatística " $t$ " com valor crítico referente a testes monocaudais e nivel de significância $\alpha=5 \%{ }^{11}$

\section{RESULTADOS E COMENTARIOS}

Os resultados obtidos nas análises bioquímicas encontram-se na Tabela 1.

Os valores de " $t$ " em relação a $\mathrm{Hb}$, apresentam-se de acordo com os esperado; as gestantes do grupo GP, com pré-natal de qualidade satisfatória e freqüência regular controlada pelo Centro de Saúde, têm niveis de concentração de $\mathrm{Hb}$ significativamente maiores do que o grupo $\mathrm{CPN}$, com atendimento pré-natal de diferentes qualidades e ainda maiores do que o grupo SPN. A diferença significante encontrada entre os grupos CPN e SPN faz sobressair a impor- 
SZARFARC, S.C. et al. Estlido comparativo de indicadores bioquímicos de concentração de ferro, em duas populaçōes de gestantes, com e sem atendimento pré-natal. Rev. Saúde públ., $\mathbf{S}$. Paulo, 16:1-6, 1982.

T A B E L A 1

Médias ( $\overline{\mathrm{X}}$ ), desvios padrão ( $\mathrm{s}$ ) e comparações das 3 populações estudadas, duas a duas (t) dos indices bloquímicos Hb, CHCM, FS e ST.

\begin{tabular}{|c|c|c|c|c|c|c|c|}
\hline \multirow{2}{*}{\multicolumn{2}{|c|}{$\begin{array}{c}\text { fndices } \\
\text { Bioquímicos }\end{array}$}} & \multicolumn{6}{|c|}{ População (n) } \\
\hline & & \multirow{2}{*}{$\frac{\mathrm{GP}(74)}{12,8}$} & \multirow{2}{*}{$\frac{\mathrm{CPN}(77)}{12,4}$} & \multirow{2}{*}{$\frac{\mathrm{GP}(74)}{12,8}$} & \multirow{2}{*}{$\underbrace{\operatorname{SPN}(77)}_{11,8}$} & \multirow{2}{*}{$\frac{\mathrm{CPN}(77)}{12,4}$} & \multirow{2}{*}{$\frac{\operatorname{SPN}(77)}{11,8}$} \\
\hline $\mathrm{Hb} \quad(\mathrm{g} / \mathrm{dl})$ & $\vec{x}$ & & & & & & \\
\hline & $\mathbf{s}$ & 1,1 & 1,3 & 1,1 & 1,6 & 1,3 & 1,6 \\
\hline & $t$ & $2,0^{*}$ & & $4,6^{*}$ & & $2,5^{*}$ & \\
\hline & $\bar{x}$ & 33,3 & 32,6 & 33,3 & 32,1 & 32,6 & 32,1 \\
\hline \multirow[t]{3}{*}{ CHCM (\%) } & $s$ & 2,0 & 1,9 & 2,0 & 2,1 & 1,9 & 2,1 \\
\hline & $\mathrm{t}$ & $2,2^{*}$ & & $3,6^{*}$ & & 1,5 & \\
\hline & $x$ & 91,6 & 79,6 & 91,6 & 78,4 & 79,6 & 78,4 \\
\hline \multirow[t]{3}{*}{$\mathrm{FS}(\mu \mathrm{g} / \mathrm{dl})$} & $\mathbf{s}$ & 37,9 & 29,6 & 37,9 & 32,4 & 29,6 & 32,4 \\
\hline & $t$ & $2,2^{*}$ & & $2,3^{*}$ & & 0,2 & \\
\hline & $\overline{\mathbf{x}}$ & 24,9 & 21,0 & 24,9 & 21,7 & 21,0 & 21,7 \\
\hline \multirow[t]{2}{*}{$\mathrm{ST}(\%)$} & s & 10,0 & 11,0 & 10,0 & 10,7 & 11,0 & 10,7 \\
\hline & $\mathrm{t}$ & $2,3^{*}$ & & $1,9^{*}$ & & 0,4 & \\
\hline
\end{tabular}

* Diferenças significativas (terit $=1,7$ ).

tância do atendimento à mulher no decorrer do processo gravídico, visto que qualquer nivel de atendimento pré-natal se associa com concentração mais elevada de Hb para as gestantes.

Considerando que a anemia ferropriva é microcitica e hipocrômica, os valores de " $t$ " observados na comparação dos 3 grupos, quanto ao $\mathrm{CHCM}$, sugerem que à medida que os cuidados de pré-natal são mais qualificados, a presença de anemia macrocítica é menos freqüente. Os grupos CPN e SPN, não se apresentando estatisticamente diferentes no que se refere à essa relação, permitem, por um lado, supor que as populações assistidas por serviço de pré-natal de diferentes qualidades ou sem esse serviço não se distinguem quanto às freqüências com que anemias micro e/ou macrocítica estão presentes. Por outro lado, evidenciam que a qualidade do pré-natal é fator de importância na qualificação desse índice bioquímico.
Novamente, quando se comparam os grupos GP, CPN e SPN em relação ao FS e ST, a importância do pré-natal é notada. A população servida por pré-natal de "acreditação" satisfatória apresenta-se com concentração de FS assim como de ST significativamente maiores do que o grupo que recebeu o pré-natal em diferentes instituiçōes, com qualidades diversas, e/ou mulheres que não receberam assistència pré-natal. Como ocorreu em relação ao $\mathrm{CHCM}$ não foi possivel distinguir os grupos CPN e SPN quanto ao FS e ao ST.

A concentração de $\mathrm{Hb}$ reflete uma situação de deficiência nutricional já estabelecida. Por ser facilmente quantificada e, principalmente, por identificar a presença de anemia, é o indice bioquímico adotado preferencialmente. Os esquemas propostos para estabelecimento de sistemas de vigilância epidemiológica nutricional 15 classificam as informações referentes à concentração de $\mathrm{Hb}$ entre gestantes, prioritárias, 
SZARFARC, S.C. et al. Estudo comparativo de indicadores bioquímicos de concentraçáo de ferro, em duas populações de gestantes, com e sem atendimento pré-natal. Rev. Saúde públ., $\mathbf{S}$. Paulo, 16:1-6, 1982.

destacando assim, a um só tempo, a importância da anemia entre os problemas de saúde pública e a importância desse indicador bioquímico no diagnóstico dessa deficiência nutricional.

O comportamento dos 3 grupos estudados em relação à $\mathrm{Hb}$ encontra-se na Figura.

Cotejando o grupo padrão com os dois grupos de gestantes CPN e SPN há que ressaltar que embora, como já foi referido, qualquer tipo de atendimento pré-natal resulta em um efeito positivo no que se refere à concentração de hemoglobina (Tabela 1), a prevalência e a severidade com que ela ocorre são maiores entre mulheres que não fizeram consultas de pré-natal do que entre mulheres que se valeram de diferentes serviços de saúde presumivelmente menos adequados do que os oferecidos por um Centro de Saúde-Escola. De acordo com o critério proposto pela OMS ${ }^{14}$ como indicador de anemia, $11,0 \mathrm{~g} \mathrm{Hb} / \mathrm{dl}$, o grupo $\mathrm{CPN}$ tem cerca de 3 vezes mais anêmicas que o grupo
GP, e o SPN 6,5 vezes mais anêmicas que o grupo GP.

A prevalência de anemia encontrada entre mulheres que não receberam atendimento pré-natal $(26,0 \%)$ está bem próxima à encontrada anteriormente em população semelhante ${ }^{12}$, quando a prevalência de valores de concentração de hemoglobina inferiores a $11 \mathrm{~g} / \mathrm{dl}$ atingiu a $23,9 \%$ das grávidas.

Para avaliar a influência da presença da anemia sobre os indices bioquimicos estudados e considerando o aumento de concentração de hemoglobina que ocorre no final da gravidez ${ }^{1,13}$, adotamos o valor $12,0 \mathrm{~g} / \mathrm{dl}$ como indicador de anemia. De acordo com esse critério verifica-se na Figura que os grupos CPN e SPN tem respectivamente 2 e 2,5 vezes mais anêmicas do que o grupo GP.

Os resultados bioquimicos foram distribuídos segundo presença ou não de anemia (Tabela 2). Os valores estatísticos resultantes da comparação dos valores encontrados entre gestantes anêmicas e náio anêmicas, encontram-se na mesma.

T A B E L A 2

Médias $(\bar{X})$, desvios padrão $(s)$ e comparação entre as pop:-lações estudadas, distribuidas segundo presença $(\mathrm{Hb}<12,0 \mathrm{~g} / \mathrm{dl}$ ) e ausência ( $\mathrm{Hb} \geqslant 12 \mathrm{~g} / \mathrm{dl}$ ) de anemia dos índices bioquímicos CHCM, FS e ST.

\begin{tabular}{|c|c|c|c|c|c|c|c|}
\hline Indi & & & & & ulação & & \\
\hline Bloqui & & $\overline{\mathrm{GP}}$ & GP & $\overline{\mathrm{CPN}}$ & CPN & $\overline{\text { SPN }}$ & SPN \\
\hline & $\bar{x}$ & 33,7 & 31,5 & 32,2 & 32,0 & 33,0 & 31,2 \\
\hline $\mathrm{CHCM}(\%)$ & $\mathbf{s}$ & 1,9 & 1,4 & 2,1 & 1,8 & 1,4 & 2,3 \\
\hline & $t$ & $4,0^{2}$ & & & & & \\
\hline & $\bar{x}$ & 92,7 & 86,6 & 85,1 & 70,5 & 79,3 & 78,6 \\
\hline $\mathrm{FS}(\mu \mathrm{g} / \mathrm{dl})$ & $\mathrm{s}$ & 37,0 & 43,2 & 28,9 & 28,9 & 34,1 & 30,5 \\
\hline & $\mathrm{t}$ & 0,5 & & 2 , & & 0 , & \\
\hline & $\bar{x}$ & 25,4 & 22,7 & 22,8 & 19,0 & 22,0 & 21,2 \\
\hline $\mathrm{ST}(\%)$ & $\mathbf{s}$ & 10,1 & 9,6 & 10,7 & 10,4 & 9,8 & 10,7 \\
\hline & $t$ & 0,9 & & 1. & & 0 , & \\
\hline
\end{tabular}

* Diferenças significativas (tcrit $=1,7$ ). 
SZARFARC, S.C. et al. Estlido comparativo de indicadores bioquímicos de concentração de ferro, em duas populações de gestantes, com e sem atendimento pré-natal. Rev. Saúde públ., $\mathrm{S}$. Paulo, 16:1-6, 1982 .

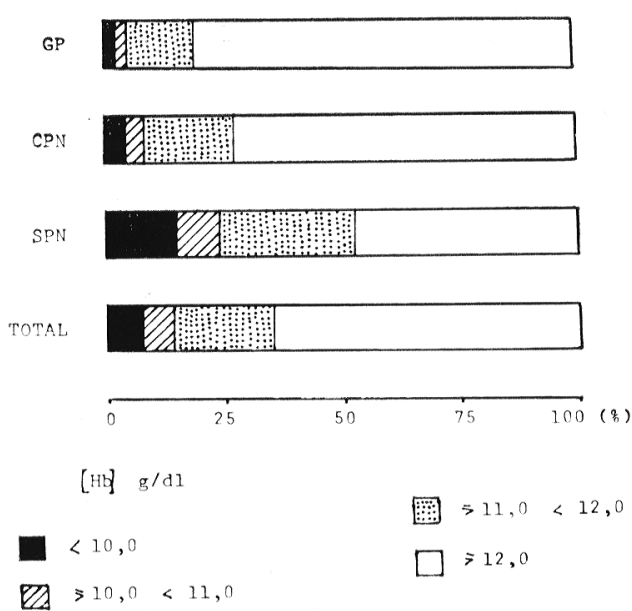

Fig. - Distribuiçāo $(\%)$ dos 3 grupos de ges. tantes estudadas segundo niveis de concentração de hemoglobina.

Os elevados valores de " $t$ " referentes à CHCM nos grupos GP e SPN chamam a atenção. De fato a anemia ferropriva sendo hipocrômica e microcítica caracteriza-se por diminuições concomitantes dos valores de $\mathrm{Hb}$ e hematócrito. Assim a maior freqüencia dessa anemia resultaria em valores de " $t$ " baixos, possivelmente não significantes. $O$ valor $t=4,0$, obtido na comparaçăo da concentração de hemoglobina corpuscular média de não-anêmicas e anêmicas do grupo padrão, sugere a presença de anemia macrocítica. Provavelmente esse resultado é conseqüência da pequena prevalência de anemia nesse grupo $(18,9 \%)$; já o valor $\mathrm{t}=4,3$ encontrado na comparação dos CHCM das mulheres sem pré-natal não pôde ser explicado à semelhança do grupo GP uma vez que seria esperado que a maior proporção de anemia, que se apresentou em $46,81 \%$ das mulheres, fosse ferropriva.

É interessante notar, em relação ao FS e ST, diferenças não significantes para os grupos GP e SPN sugerindo, que no grupo GP a depleção de ferro sérico, que ocorre no final da gravidez, seja próprio do estado fisiológico da mulher ${ }^{13}$, e que no grupo
SPN a deficiência de ferro ocorra em niveis patológicos com ou sem anemia.

Verifica-se, através dos dados apresentados, que a assistência de saúde à mulher no periodo gravidico é altamente recomendável para a evolução normal da gravidez e que a quantidade de consultas aliada à sua qualidade são fatores relevantes para corroborar com essa evolução.

Embora exista preocupação em nível estadual e federal de combater a anemia ferropriva através do acompanhamento da mulher com consultas médicas no período gestacional e suplementação medicamentosa de ferro, os resultados observados apontam a deficiência de ferro como sendo um problema de saúde pública de grande prevalência. É também necessário referir que, se os programas de saúde materna estão sendo implementados, a cobertura álcançada pelos serviços de saúde é ainda baixa e a sua qualidade heterogênea.

\section{CONCLUSסES}

Os resultados obtidos nas análises de indices bioquímicos em três grupos de gestantes levam às seguintes conclusões:

- o atendimento pré-natal se associa com concentração de hemoglobina mais elevada quando comparada com grupo sem atendimento pré-natal.

- o grupo padrão apresentou índices bioquimicos referentes ao ferro, hemoglobina, volume corpuscular médio de hemoglobina, ferro sérico e saturação de transferrina, significativamente mais adequados quando comparados com os outros dois grupos.

- a prevalência de anemia decresceu significativamente do grupo sem pré-natal para o grupo padrão.

- comparando-se, para cada estrato populacional, os indices bioquímicos entre grávidas anêmicas e não-anêmicas verificou-se no grupo padrão e no sem atendimento pré-natal, diferenças não significantes no que se refere a ferro sérico e a saturação de transferrina. 
SZARFARC, S.C. et al. Estudo comparativo de irdicadores bioquímicos de concentração de ferro, em duas populações de gestantes, com e sem atendimento pré-natal. Rev. Saúde públ., $\mathbf{S}$. Paulo, 16:1-6, 1982.

SZARFARC, S.C. et al. [A comparative study of biochemical indicators of iron concentration in two groups of pregnant women, with and without pre-natal care]. Rev. Saúde públ., S. Paulo, 16:1-6, 1982.

ABSTRACT: The influence of the amount of pre-natal care on the prevalence of iron-deficiency among women, 36 weeks or more pregnant, was assessed. The sample population was divided into three groups: the Standard Group (GP) — with adequate assistance of the pre-natal care services from the first trimester of pregnancy onwards; those who received pre-natal assistance, but of varying adequacy and begun at different gestational ages (CPN); and those who received no pre-natal assistance at all (SPN). The results obtained from hemoglobin analysis showed that prevalence and severity of anemia increases significantly from the GP to the SPN. The analysis of the mean corpuscular hemoglobin concentration, serum iron and transferrin saturation showed no statistically significant differences between groups CPN and SPN; the GP showed better results when compared to the other two. Attention is called to the necessity of pre-natal care and the standardization of its quality with a view to diminishing the prevalence of iron-deficiency among pregnant women.

UNITERMS: Pregnancy. Anemic hypochronic. Pre-natal care.

\section{REFERENCIAS BIBLIOGRAFICAS}

1. Almeida, P.A.M. de et al. Curva de hemoglobina em um gripo de gestantes normais. Rev. Saúde puibl., S, Paulo, 'i:273$82,1973$.

2. BOTHWELI, T. H. \& MALi I' $\mathbf{3}$, B. The determination of iron in plasma serum. Biochem. J., 59:599-602, 1955.

3. CIARI Jr., C. \& ALMEIDA, P.A.M. de Elementos de avaliação do "risco gravídico". Rev. Saúde puibl., S. Paulo, 6:57-78, 1972

4. CIARI Jr., C. et al. "Acreditação" de serviços de pré-natal. Rev. Saúde públ., S. Paulo, 8:187-202, 1974.

5. DElascio, D. \& ALMeida, P.A.M. Propedeutica da gestação de alto risco. São Paulo, Livraria Manole, 1974.

6. NESBITT, R.E.L. \& AUBRY, R.H. High-risk obstetrics. Amer. J. Obstet. Gynec. $103: 972-85,1969$.

7. PERKIN, G.W. Assessment of reproductive risk in nonpregnant women. Amer. $J$. Obstet. Gynec., 101:709-17, 1968.

8. SCHADE, A.L. et al. Bound iron and unsaturated iron-binding capacity of serum, rapid and reliable quantitative determination. Proc. Soc. exp. Biol., 87:443-8, 1954
9. SECRETARIA DE ESTADO DA SAUDE. Coordenadoria de Saúde da Comunidade. Programa de assistência às gestantes revisão 1978. São Paulo, 1978. [mimeografado].

10. SOKOL, R.J. et al. Clinical application of high risk scoring on an obstetric service. Amer. J. Obstet. Gynec., 128:652-61, 1977.

11. SPIEGEL, M.R. Estatistica. 9a ed. Rio de Janeiro, Mc Graw-Hill do Brasil, 1976.

12. SZARFARC, S.C. Anemia ferropriva em parturientes e recém-nascido. Rev. Saúde públ., S. Paulo, 8:369-74, 1974.

13. SZARFARC, S.C. et al. Avaliação da concentração de ferro em uma população de gestantes. [Apresentado no XI Congresso Internacional de Nutriçăo, Rio de Janeiro, 1978],

14. WORLD HEALTH ORGANIZATION. Expert Committee on the Prevention of Perinatal Mortality and Morbidity, Geneva, 1969. Report. Geneva, 1970. (Techn. Rep. Ser., 457).

15. WORLD HEALTH ORGANIZATION. Risk approach for maternal and child health care, Geneva, 1978. (Offset publ., 39).

Recebido para publicasão em 04/02/1981 Aprovado para publicaşão em 07/10/1981 